\title{
Removal of Air Containing Tri Ethyl Amine (TEA) Using Vapor Phase Biofilter Packed With Wood Chips and Rice Husk
}

\author{
Bharath Gandu, K. Sandya, A. Gangagni Rao and Y.V. Swamy
}

\begin{abstract}
Mixed bacterial strains named as AGR/IICT/1$5 B$ was isolated from the active sludge of ETP of a polymerization industry. Strains AGR/IICT/1-5B was primarily identified as 3 gram positive and 2 gram negative bacteria. These strains were used for the abatement of TEA in bio filters. Experiments were conducted on biofilter having the working volume of $1.2 \mathrm{~L}$. Microorganism was immobilized on mixture of wood chips and rice husk $(1: 1 \mathrm{v} / \mathrm{v})$ which is used as the filter medium. The biofilter was operated at the following conditions; Temperature $30 \pm l^{\circ} \mathrm{C}, \mathrm{pH}$ values in the range of 7.0 -7.6, Loading rate at $1-144 \mathrm{~g} \mathrm{~m} \mathrm{~h}^{-3}$, EBRT at 20-40 s, moisture content at 50-59\%. Removal efficiency in the range of $90-95 \%$ was obtained during the study.
\end{abstract}

Keywords--- Biofiltration, Triethylamine, Biodegradation, Air Pollution

\section{INTRODUCTION}

$\mathrm{A}$ MINES, especially Triethylamine (TEA) are widely used as a catalyst for polymerization reactions and corrosion inhibitor in industry [1]. It is also used as an intermediate in the production of various chemicals, pesticides, desalination of sea water [2]. TEA is one of the amines emitted from cattle feedlots [3]. TEA emissions causes adverse effect on environment. In addition, TEA is malodorous and can endanger human health [4]. Animal experiments have revealed that TEA could cause irritation to the dermal, ocular and respiratory systems and long term exposure to TEA could result in abnormal embryos. TEA has been considered to be a possible carcinogen [5]. Therefore, it is necessary to remove TEA from the environment. Moreover, adoption of stricter emission policies in recent years has greatly increased the inventory of compounds TEA is one of the compound [6]. Several physical and chemical methods have been proposed for treating TEA. But physicochemical methods have high

Bharath Gandu, Bioengineering and Environmental Centre (BEEC), Indian Institute of Chemical Technology (IICT), Hyderabad, India.

$K$. Sandya, Bioengineering and Environmental Centre (BEEC), Indian Institute of Chemical Technology (IICT), Hyderabad, India.

A. Gangagni Rao, Bioengineering and Environmental Centre (BEEC), Indian Institute of Chemical Technology (IICT), Hyderabad, India. E-mail: gangagnirao@gmail.com

Y.V. Swamy, Bioengineering and Environmental Centre (BEEC), Indian Institute of Chemical Technology (IICT), Hyderabad, India. treatment costs and may cause secondary pollution. Hence biological methods of treatment have emerged as an effective and inexpensive alternative to conventional physicochemical treatment systems for treating large air streams with low concentrations. The technology is still under developmental stage in terms of economics, equipment design, process kinetics and operational skills. Different layouts and design are e being proposed including biofiltration, biotrickling filter, and bioscrubber [7] in biological process scheme. In biofiltration, contaminated air to be treated is passed through a packed bed where biodegradable gases or volatile compounds are absorbed into the biofilm in which diffusion and aerobic biodegradation occur simultaneously in a complex set of physical, chemical and biological interactions. This study was conducted to investigate the performance of biofiltration system in treating TEA gas under various conditions of inlet concentration, moisture content, $\mathrm{pH}$, pollutant loading rate and empty bed residence time (EBRT).

\section{MATERIALS AND METHODS}

Seed Source: Enrichment and immobilization of microbial cultures for seeding to the bio filter were isolated from the activated sludge of ETP collected from polymerization industry. Sludge was analyzed for various important parameters like total suspended solids (TSS) and volatile suspended solids (VSS) and found that TSS was f 48,000 mg/l and VSS was $25,000 \mathrm{mg} / \mathrm{l}$. The $\mathrm{pH}$ of the sludge was 8 .

\section{A. Enrichment and Isolation}

An activated TEA sludge effluent sample from seed source (5ml) was added to $100 \mathrm{ml}$ mineral salt media (MSM) containing $100 \mathrm{mg}^{-1}$ TEA, which was used as the sole carbon and nitrogen source, and it was incubated on a rotary shaker at $30^{\circ} \mathrm{C}$ and $150 \mathrm{rpm}$ for 4 days. The media $\mathrm{pH}$ was adjusted to 7.0. Five milliliters culture was then sub cultured in to fresh MSM containing TEA every 4 days for enrichment up to 10 generations. Enrichment cultures capable of degrading TEA were diluted and spread on to MSM agar containing gradient 50-300 $\mathrm{mg}^{-1}$ TEA and colonies grown on plates were tested for their TEA-degrading capabilities. These plates were kept in an incubator at a temperature of $37^{\circ} \mathrm{C}$ for 3 days. Same procedure was repeated for 4-5 times to get acclimatized TEA Oxidizing bacteria. Five strains, designated as AGR/IICT/1$5 \mathrm{~B}$, which possessed the highest TEA degrading ability and could, utilize TEA as a sole carbon and nitrogen source for growth. These isolated microorganisms were used for further investigation. 


\section{B. Bio-Filter Packing Material}

The wood chips and rice husks were obtained from the local market of Hyderabad. The filter material was characterized for various parameters like dry weight, particle size, moisture content (wet based), bulk density, water holding capacity and $\mathrm{pH}$. The bio filter was packed with a mixture of Wood chips and rice husks in a ratio 1:1 ( $/ / \mathrm{v})$ as the medium for bio film attachment.

\section{Immobilization}

Bio filter packing material was used as the nutrient support for bacteria. Enriched mixed strains were grown in 1L MSM broth for four day before being harvested by centrifugation at $7200 \mathrm{rpm}$ for $15 \mathrm{~min}$. The pellets were put into a $5 \mathrm{~L}$ conical flask containing $1 \mathrm{~L}$ of MSM broth for bacterial growth. About $1 \mathrm{~kg}$ of bio filter material was mixed with the above solution for bacterial attachment. Fresh broth was added every three days until the number reached about $3.4 * 10^{-8} \mathrm{CFU} / \mathrm{g}$-bio filter material. The microbial cell laden bio filter material was then packed into the bio filter.

\section{Bio Filter Setup and Operation}

The bio filter was cylindrical glass column having inner diameter of $8.1 \mathrm{~cm}$ and height of $70 \mathrm{~cm}$. Immobilized bio filter packing material was filled up to $50 \mathrm{~cm}$ height in the glass column. The bio filter column was provided with two sampling ports along the length of column. The polluted air was supplied by using an aqueous air pump. The air stream was allowed to strip through a $250 \mathrm{ml}$ impinger containing different concentrations of TEA solution, air flow rates was controlled with a regulatory knob of air pump for producing TEA of desired concentration. The contaminated air stream was then fed to the bio filter column at the top and the bio filter was operated in the down flow mode. The filter was operated continuously for 150 days and during the operation period ambient temperature was around $30^{\circ} \mathrm{C}$. The biodegradation of TEA vapor was investigated at various inlet concentrations, flow rates. Moisture content (MC), $\mathrm{pH}$, pressure drop was measured during the operation period periodically. The nutrient solution was prepared and sprinkled on bio filter media for bio stimulation in initial days. Air stream was regularly collected from the inlet and outlet sampling ports and analyzed. The performance of the biofilter was evaluated in terms of removal efficiency (RE) and elimination capacity (EC) as a function of pollutant loading.

\section{ANALYTICAL METHODS}

\section{A. TEA Concentrations}

Inlet and outlet TEA concentrations in the bio filtration process were measured periodically by using RAE analyzer (Tokyo, Japan). In the biofilter bed material TEA biodegradation releases the nitrogen from in the form of ammonia $\left(\mathrm{NH}_{3}-\mathrm{N}\right)$ which may be further oxidized to nitrite $\left(\mathrm{NO}_{2}-\mathrm{N}\right)$ and nitrate, $\left(\mathrm{NO}_{3}-\mathrm{N}\right)$ and therefore $\mathrm{NH}_{3}-\mathrm{N}, \mathrm{NO}_{2}-\mathrm{N}$ and $\mathrm{NO}_{3}-\mathrm{N}$ were analyzed in the biofilter material using a UV-visible (Perkin Elmer lambda 25) spectrophotometer as per standard methods [8].

\section{B. Microbial Analysis}

The microorganism concentration in the bio filter was measured, as the number of colony forming units (CFU) per gram of packing material at initial, final and different time intervals. One gram of packing material (rice husk and wood chips) was taken from the biofilter column. Initially $100 \mathrm{ml}$ of sterilized distilled water was taken and added to $1 \mathrm{~g}$ of collected sample of packing material. This solution was shaken vigorously in a shaker for $30 \mathrm{~min}$ and serially diluted with sterilized water. Then the plating was carried out on nutrient agar media in Petri dishes under aseptic conditions. The Petri dishes were incubated in the incubator (Lab tech instruments, Model: $1 \mathrm{bi}-150 \mathrm{M}$ ) for two days at $37^{\circ} \mathrm{c}$. Then the colonies were counted to obtain the CFU. The isolated microbial cultures (from enrichment, isolation step) were identified primarily using gram sating method [9].

\section{Measurement Flow Rate, MC, Temperature, Ph and Pressure Drop}

Temperature was measured with mercuric thermometer, $\mathrm{pH}$ was determined with Elico $\mathrm{pH}$ meter, pressure drop was measured using U-tube manometer and MC was determined as per standard methods [8]. Biofilter air flow rate was measured by water displacement technique.

\section{RESUlTS AND DisCUSSION}

It could be observed that biofilter bedding material was having the bulk density of $0.61 \mathrm{~g} / \mathrm{cc}, \mathrm{MC}$ of $65 \%, \mathrm{pH}$ of 7.0 and water holding capacity of $81 \%$. These characteristics indicated that wood chips and rice husk had most of the favorable properties of a good biofilter medium. During the entire period of operation more or less constant pressure drop $5 \mathrm{~mm}$ of water column was observed across the bed which indicated a low operational cost and presence of biofilm of constant thickness in the biofilter. In addition to low pressure drop, negligible deterioration and compaction of the bed were observed indicating a good mechanical strength of the media. Enriched and isolated cultures in biofilter column primarily observed as three gram positive and two gram negative bacteria.

\section{A. Performance of Biofilter}

The performance of bio filter for TEA degradation was studied under distinct phases as shown in table 1 and figure 1 . Initially the biofilter was operated at a low concentration in the range of 2.34-8.28 parts per million in volume $(\mathrm{ppmV})$ of TEA, flow rate was $0.108 \mathrm{~m}^{3} \mathrm{~h}^{-1}$ and EBRT was $40 \mathrm{sec}$ to facilitate a proper microbial growth and establish steady state conditions. Steady state was achieved on the 10th day of operation which was evident from the constant value of RE $(>90 \%)$. Thus, it is concluded that about 10 days were needed for proper acclimation of enriched strains over packing material for effective degradation of TEA. On the 11th day, the inlet concentration was gradually increased up to $48 \mathrm{ppmV}$ (Phase I). In this phase, TEA inlet concentration was varied between 0.05 to $0.20 \mathrm{~g} \mathrm{~m}^{-3}$ and RE reached up to $97 \%$. In this phase (phase II) MC of the biofilter was reduced below 50\% in order to observe the RE of the filter. It was observed that $\mathrm{RE}$ was decreased in the rage of $30-60 \%$ due to less microbial 
biodegradation activity at low MC. In Phase III, the MC again maintained in the range of $55-59 \%$ based on results obtained from phase I, TEA inlet concentration was further increased up to $286 \mathrm{ppmV}$, during this phase TEA removal efficiency gradually increased to $95 \%$. Further, when the concentration was increased from 286 to $396 \mathrm{ppmV}\left(104.5\right.$ to $\left.144 \mathrm{~g} \mathrm{~m}^{-3}\right)$ in this phase(IV) significant effect on the biofilter performance that is RE was decreased up to $50 \%$ even optimum moisture content maintained. This might be microorganism's biodegradation activity suppressed due to high inlet concentrations. It indicates in this phase organisms are not active these forms might be spores are formed. The biofilter was then shutdown for 5 days. After the shutdown period, the bio filter was operated again (Phase V). The TEA inlet concentration was started at $130 \mathrm{ppmV}$, it reaches maximum RE .It indicates a very stable biofilm in the biofilter during the shutdown period also. Similarly in final Phase (phase VI) the gas flow rate was increased and maintained at $0.217 \mathrm{~m}^{3} \mathrm{~h}^{-1}$ with a corresponding EBRT of $20 \mathrm{sec}$ and the TEA inlet concentration was varied between 174 to $224 \mathrm{ppmV}$. The removal efficiency slightly fluctuated and then stabilized at 90 to $98 \%$ by the end of this phase. During these all phases, the inlet TEA concentration and flow rate were varied in between 12-286 ppmV and $0.108-0.217 \mathrm{~m}^{3} \mathrm{~h}^{-1}$, respectively. It shows this Biofilter was responded very quickly to changes in flow rate and inlet concentrations and achieved nearly the higher level of removal efficiency at optimum conditions (except in phase II \& IV).One important finding was observed loading rate is not a critical parameter in this biofilter only concentration of ppmV was critical parameter. Bio filter Initial $\mathrm{pH}$ was 7.0 but it increased slowly over the time and stabilized at around 7.6. This may be due to the production of ammonia. The $\mathrm{pH}$ variation (7-7.6) during entire experimental run was very favorable for the growth of enriched microbial culture [10].

Table 1: Biofiltration of TEA: Range of Operating Conditions

\begin{tabular}{|c|c|c|c|c|c|c|c|}
\hline Phase & $\begin{array}{c}\text { Flow } \\
\text { rate( } \mathrm{m}^{3} \\
/ \mathrm{hr})\end{array}$ & EBRT & $\mathrm{Ci}(\mathrm{PPMV})$ & $\begin{array}{c}\text { Inlet load } \\
\left(\mathrm{g} / \mathrm{m}^{3}\right)\end{array}$ & $\begin{array}{c}\text { Days of } \\
\text { operation }\end{array}$ & $\mathrm{MC}(\%)$ & $\mathrm{RE}(\%)$ \\
\hline $\begin{array}{c}\text { Acclimatization } \\
\text { phase }\end{array}$ & 0.108 & 40 & $2.34-8.24$ & $0.01-0.03$ & 10 & $>55-<60$ & $>92$ \\
\hline Phase1 & 0.108 & 40 & $12-48$ & $0.05-0.20$ & 22 & - DO- & $85-99$ \\
\hline Phase II & 0.108 & 40 & $49-63$ & $0.20-0.26$ & 12 & $<55$ & $32-78$ \\
\hline Phase III & 0.108 & 40 & $66-286$ & $0.27-1.17$ & 75 & $>55-<60$ & $77-95$ \\
\hline Phase IV & 0.108 & 40 & $286-396$ & $1.17-1.62$ & 25 & - DO- & $22-89$ \\
\hline Shut down & - & - & - & - & 5 & - & - \\
\hline Phase V & 0.108 & 40 & $130-179$ & $0.53-0.73$ & 12 & - DO- & $73-91$ \\
\hline Phase VI & 0.217 & 20 & $134-224$ & $0.55-0.92$ & 30 & - DO- & $91-98$ \\
\hline
\end{tabular}

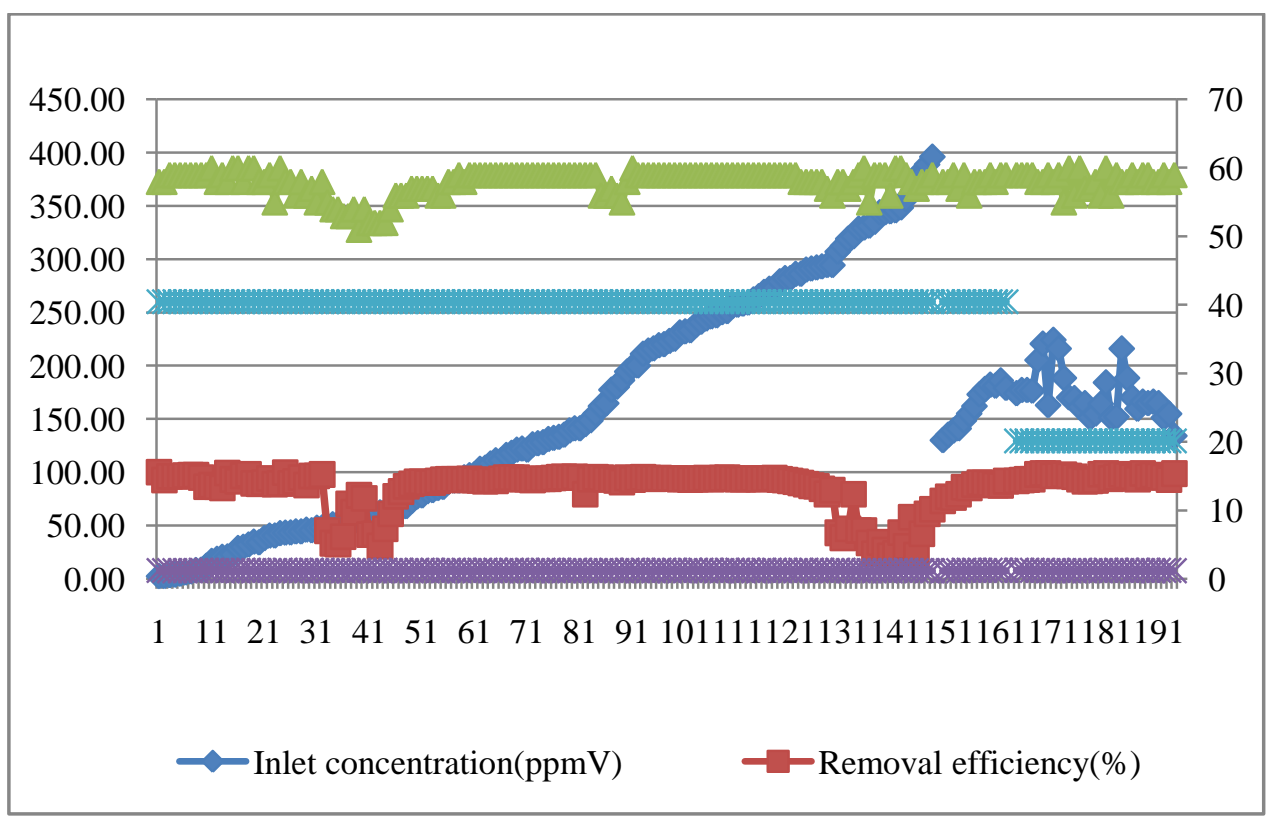

Figure 1: Biofilter Performance 


\section{REFERENCES}

[1] Åkesson T. Florén, S. Skerfving, "Visual disturbances after experimental human exposure to triethylamine", Br. J. Ind. Med. 45, Pp. 262- 268, 1988.

[2] The Merck Index. An Encyclopedia of Chemicals, Drugs, and Biologicals. 11th ed. Ed. S. Budavari. Merck and Co. Inc., Rahway, NJ. 1989.

[3] Mosier AR, Andre CE, Viets FG Jr. Identification of aliphatic amines volatilized from cattle feedyard. Environ. Sci. Technol. 7, Pp. 642-644, 1973.

[4] L. Belin, U. Wass, G. Audunsson, I. Mathiasson, "Amines possible causative agents in the development of bronchial hyperreactivity in workers manufacturing polyurethanes from isocyanates", Br. J. Ind. Med. 40, Pp. 251-257, 1983.

[5] Aimin. H, Cao, L.X, Jie, C, Spiess, F.J, Steven, L.S, Timothy, N.O, Steve, O.H, James, D.F, "Photocatalytic degradation of triethylamine on titanium oxide thin films", J. Catal. 188, Pp. 40-47, 1999.

[6] U.S. Department of Health and Human Services. Hazardous Substances Data Bank (HSDB, online database). National Toxicology Information Program, National Library of Medicine, Bethesda, MD. 1993.

[7] Burgess J.E., S.A. Parsons, R.M. Stuets, "Development in odors control and waste gas treatment biotechnology" a review. Biotechnol. Adv., 19, Pp. 35-63, 2001.

[8] APHA, Standard Methods for the Examination of Water and Wastewater, 20th ed. APHA, AWWA, WEF, Washington, D.C. 1998.

[9] Krieg N.R., Holt J.G. (Eds.), "Bergeys Manual of Systematic Bacteriology", Vol. 1. Williams and Wilkins, USA 1984.

[10] Gangagni Rao, A., P.Ravichnadra, Annapurna Jetty, "Operation of biofilter with mixed agricultural residue as filter material: Effects of humidification and inlet hydrogen sulphide volume fraction on the performance", Chem. \& Biochem.Eng. Q., 20 (2), Pp. 189-196, 1996 